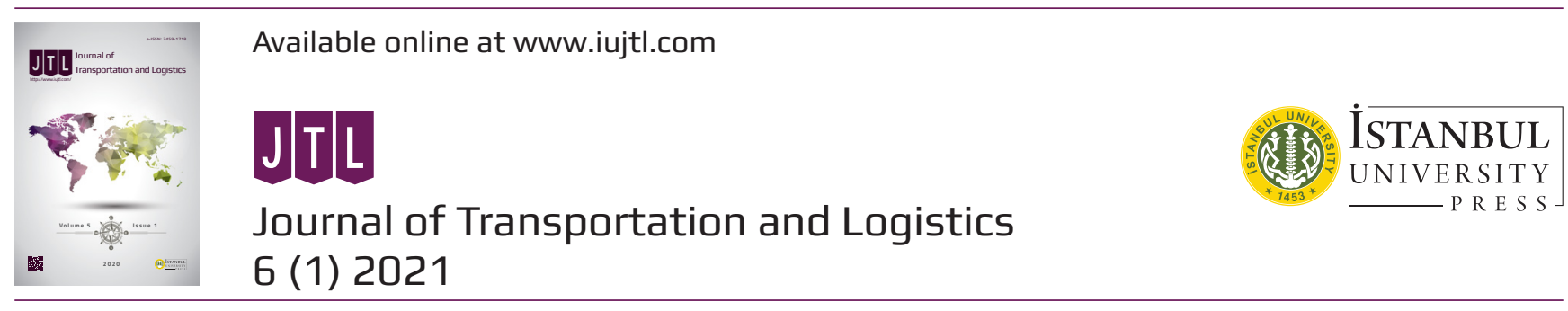

\title{
Tarım-Gıda Tedarik Zincirinde Ağ Tasarımı ve Optimizasyonu: Bir Meyve Suyu İșletmesi Örneği
}

\author{
Network Design and Optimization in the Agri-Food Supply Chain: A Juice Business \\ Example
}

\author{
Belkız Torğul' ${ }^{1}$, Enes Demiralay² (i), Turan Paksoy³ (i)
}

\section{öz}

Tarımsal gıdalara ulaşamamak günümüzde yaygınlaşmaya başlayan büyük bir sorun haline gelmiştir. Tarımsal gıda tedarik zincirleri, gıda güvenliği ve halk sağlığı ile ilgili sorunlar nedeniyle son yıllarda tüketiciler, firmalar, devlet kurumları ve araştırmacıların daha fazla ilgisini çekmektedir. İnsanların yaşamını sağıkılı bir şekilde devam ettirebilmesi için en önemli ihtiyacı olan tarımsal gıdaların tedarik süreci çerçevesinde son yıllarda tüm dünyanın ilgisini çeken sürdürülebilirlik konusuna da yer verilmelidir. Bir tarımsal gıda tedarik zincirinin sürdürülebilirliğini etkileyen en kritik faktörlerden biri ağ tasarımıdır. Bu yüzden, tarımsal tedarik zincirlerinin tasarımı ve işletilmesi daha sıkı düzenlemelere tabi olmalıdır. Bu çalışmada, gıda tedarik zincirlerinin tasarımı için öncelikle operasyonel araştırma yöntemlerinin bir literatür incelemesi verilmiş ardından şeftali suyu ürünlerinin tedarik zinciri sürdürülebilirliği için yeni bir kapalı döngü ağ tasarımı uygulaması sunulmuştur. Şeftali suyu tedarik zinciri ağ tasarım modeli, karma tamsayılı doğrusal programlamaya dayalı olarak kârı maksimize etmek üzere formüle edilmiş ve sayısal bir örnek yardımıyla GAMS programında çözülerek doğrulanmıştır. Önerilen model, çiftçi-tedarikçi seçimi, taşıma ve dağıtım sorunlarını ele alırken geri dönüşüm süreci ile maliyet düşürme, çevrenin korunması ve atıkların ekonomiye kazandıııması faaliyetlerini ön plana çıkarmaktadır. Modelin çözüm sonuçları, ele alınan gıda- tedarik zincirinde en fazla mali giderlerin satın alma kalemi olduğunu ortaya koymuştur. Yapılan duyarlıık analizi ile çiftçilerden yeterli arz sağlanması yoluyla daha kısa tedarik zinciri oluşturmanın işletmeye hem ekonomik hem de çevresel olarak katkı sağlayacağı sonucuna varılmıştır.

Anahtar Kelimeler: Ağ Tasarımı, Geri Dönüşüm, Karma Tamsayılı Doğrusal Programlama, Tarım-Gıda Tedarik Zinciri

\section{ABSTRACT}

Lack of access to agriculture-based food has become a major problem that is becoming increasingly widespread. Agri-food supply chains have attracted growing attention from consumers, companies, government agencies, and researchers in recent years due to problems with food safety and related public health issues. Sustainability, which has attracted global attention in recent years, should also be included within the optimal framework of the process of supplying agricultural food, which is among the most important needs people face in order to live healthy lives. One of the most critical factors affecting the agri-food supply chain's sustainability is network design. Therefore, the design and operation of agri-food supply chains should be subject to stricter regulations. In this study, we conduct a literature review of operational research methods used in the design of agricultural food supply chains, and present a new, closed-loop network design application for supply chain sustainability of peach juice products. The peach juice supply chain network design model was formulated using linear programming to maximize profit and was verified using the GAMS program with the help of a numerical example. The proposed model framework highlights cost reduction activities within the recycling process, protecting the environment, and recovery the waste to the economy while addressing farmer-supplier selection, transportation, and distribution problems.

Keywords: Network Design, Mixed Integer Linear Programming, Recycling, Agri-Food Supply Chain

Başvuru/Submitted: 13.03.2021 • Revizyon Talebi/Revision Requested: 04.05.2021 • Son Revizyon/Last Revision Received: $25.05 .2021 \bullet$ Kabul/Accepted: 26.05 .2021

\footnotetext{
1 Sorumlu yazar/Corresponding author: Belkız Torğul (Arş. Gör.), Konya Teknik Üniversitesi, Mühendislik ve Doğa Bilimleri Fakültesi, Endüstri Mühendisliği Bölümü, Konya, Türkiye E-mail: belkistorgul@gmail.com ORCID: 0000-0002-7341-9334

2 Enes Demiralay (Arş. Gör.), Konya Teknik Üniversitesi, Mühendislik ve Doğa Bilimleri Fakültesi, Endüstri Mühendisliği Bölümü, Konya, Türkiye E-mail: edemiralay@ktun.edu.tr ORCID: 0000-0003-1383-3645

3 Turan Paksoy (Prof. Dr.), Necmettin Erbakan Üniversitesi, Havacılık ve Uzay Bilimleri Fakültesi, Havacılık Yönetimi Bölümü, Konya, Türkiye E-mail: tpaksoy@yahoo.com ORCID: 0000-0001-8051-8560

Atıf/Citation: Torgul, B., Demiralay, E., \& Paksoy, T. (2021). Tarım-gıda tedarik zincirinde ağ tasarımı ve optimizasyonu: bir meyve suyu işletmesi örneği. Journal of Transportation and Logistics, 6(1), 49-70. https://doi.org/10.26650/JTL.2021.896101
} 


\section{EXTENDED ABSTRACT}

Globalization and an increase in exports are playing a progressively important role in expanding supply chains (SCs) over wide areas. In addition, Supply Chain Management (SCM) has been gaining strategic importance in terms of its impact on the success of companies that have become business partners and/or competitors across different geographic areas. Suppliers, production facilities, distribution facilities, storage facilities, and collection and recovery facilities are members of the SC, and SCs are dynamic processes involving a continuous flow of materials, funds, and information within and between these members across multiple functional areas. SCM determines and oversees the number of entities, locations, capacities, and flows between SC members. The dynamics of SCM have changed over the years, as new paradigms have developed in order to respond to increasing environmental concerns and customer pressures. Lack of access to agricultural food has become a major problem. Agri-food SCs are attracting more attention from consumers, companies, government agencies, and researchers due to problems with food safety and related public health concerns. Sustainability, which has attracted global attention in recent years, should also be included within the framework of supplying agricultural food, which is the most important need for people to live healthy lives. Increasing environmental concerns, the impacts of climate change, socialenvironmental awareness, legal regulations of governments, declining resources and profit margins have increased the need and importance of sustainability. By collecting used products from end-users as part of the supply process, SCs have become cyclical and sustainable structures. Based on this transformed structure, the concept of "ClosedLoop SCM" (CLSC) or "Sustainable SCM" has emerged. One of the most critical factors affecting agri-food supply chain sustainability is network design. Therefore, we propose that the design and operation of agri-food supply chains, including network design, should be subject to stricter regulations.

In this study, we first provide a literature review of operational research methods regarding the design of agricultural food SCs. Then, we present a new closed-loop network design application for a sustainable supply chain for peach juice products. In the processed peach products supply chain farmers are the main suppliers of raw materials. In addition to buying from farmers, producers sometimes obtain raw materials from large traders (second-tier suppliers). In these cases, the supply chain is extended as raw materials are not purchased directly from the farmers. Distributors distribute peach juice from the manufacturer to retailers or consumers, but retailers are the preferred distribution channel for manufacturers in marketing their peach juice products, as peach juice consumers consist of local consumers living in various regions. The manufacturer processes the peaches, which are procured from farmers or second-tier suppliers in June, July, and August, in their production center. Peach juice is delivered to the distribution and collection center, and from there it is forwarded to retailers, who are the customers. The company works in cooperation with the glass bottle supplier and packaging facilities to package their final products. In addition, it produces their products in accordance with environment friendly, sustainable agriculture food sector practices by selling the pulp produced during the production phase to be turned into organic fertilizer, and by collecting at least some 
of the used glass bottles from customers. The collected glass bottles that are suitable are then disinfected and reused in the production center, and the others are sold to a recycling center and then to the glass bottle supplier for reprocessing.

The model developed to analyze the problem of optimizing the agri-food supply chain network design was formulated based on mixed integer linear programming with the objective function of maximizing profit, and was verified by solving it in the GAMS program using a numerical example. The model framework presented in this study highlights the cost reduction activities within the recycling process, protecting the environment, and recovering the manufacturing waste into the economy while addressing farmer-supplier selection, transportation, and distribution problems. It also provides examples of how to overcome problems that often arise in agri-food systems, offering guidance to practitioners on key issues to be included in network design of agri-food supply chains. This peach juice production process implementation study serves as an example for presenting these modeling and optimization strategies and can be applied to a wide variety of agri-food SCs with similar characteristics. 


\section{Giriș}

Günümüzde küreselleşme ve ihracattaki artış ile işletmelerin Tedarik Zinciri (TZ) geniş bir alana dağılmış ve farklı coğrafyalarda iş ortağ 1 ve/veya rakip haline gelen işletmelerin arasında artan rekabet TZ'nin stratejik bir önem kazanmasına neden olmuştur. Tedarikçiler, üretim tesisleri, dağıtım tesisleri, depolama tesisleri, toplama ve geri kazanım tesisleri TZ'yi oluşturan üyelerdir ve TZ bu üyeler içinde ve arasında çok sayıda işlevsel alanda sürekli malzeme, fon ve bilgi akışını içeren dinamik bir süreçtir (Jain vd., 2009). TZ üyelerinin sayısının, yerinin, kapasitesinin ve aralarındaki akışların belirlenmesine Tedarik Zinciri Yönetimi (TZY) adı verilir. TZY'nin dinamikleri yıllar içinde değişmiş, artan çevresel kaygılar ve müşteri baskılarına cevap verebilmek için yeni paradigmalar TZY'ye eklenmiştir.

Artan çevresel kaygılar, iklim değişiklilerinin artan etkisi, toplumsal çevre bilincinin artması, hükümetlerin yasal düzenlemeleri, azalan kaynaklar ve kâr marjları sürdürülebilirliğe olan ihtiyacı ve önemi arttırmıştır. Bu süreçte son kullanıcılardan kullanılmış ürünlerin toplanmasıyla $\mathrm{TZ}$ döngüsel ve sürdürülebilir bir yapıya dönüşmüştür. Bu dönüşmüş yapıyla birlikte "Kapalı Döngü Tedarik Zinciri Yönetimi” (KDTZ) veya "Sürdürülebilir Tedarik Zinciri Yönetimi” kavramı ortaya çıkmıştır. Artmakta olan çevresel bilinç ve sürdürülebilirliğin önemi nedeniyle, Sürdürülebilir TZY akademisyenlerden ve uygulayıcılardan daha fazla ilgi görmeye başlamıştır. Literatürde Sürdürülebilirlik, Üçlü Kârlılık Yaklaşımı (Triple Bottomline-TBL Approach) adı verilen bu yapı üç ana sütun üzerinde tanımlanmaktadır; ekonomik, çevresel ve sosyal faktörler. Son araştırmalar, sürdürülebilir araç ve yöntemlerin entegre kullanımının kuruluşlarda bir sinerji yarattı̆̆ını ve aynı anda hem operasyonel hem de çevresel performansı artırdığını göstermektedir (Paksoy vd., 2019). Bu aslında çok şaşırtıcı değildir. Çünkü sürekli iyileştirme için kullanılan en popüler ekonomik paradigmalardan biri olan Yalın Üretimin temel amaçlarından israfların yani mudaların azaltılması (malzeme, su, enerji vb.), doğrudan yeşil felsefe ile de örtüşmektedir.

19. yüzyılın ikinci yarısından beri, gıda sistemi küreselleşme olgusundan güçlü bir şekilde etkilenmiştir. Çiftçiler ve tüketiciler arasındaki doğrudan ilişkilerin yerini, çeşitli aracıları içeren karmaşık bir aktörler sistemi almıştır (Dunne vd., 2011). Büyük toptancılar ve süpermarket zincirlerinden oluşan bir pazara giriş, küçük çiftçilerin aleyhine rekabeti artırmıştır (Renting vd., 2003). Üretilen toplam gıdanın yaklaşık \%30-35'i, yetersiz altyapı ve etkisiz TZ nedeniyle her yıl israf edilmektedir (Parwez, 2014). Küreselleşme ayrıca biyolojik çeşitlilik ve ekosistemlerde bir çöküşe, obeziteye ve gıda yoksulluğunun artmasına ve tüketicilerin gıda kaynağı ve kalitesi hakkında yeterli bilgiye sahip olmasının imkansızlığına neden olmuştur (Pulker vd., 2018; Qaim, 2017). Bununla birlikte, günümüzde tüketiciler, küreselleşmiş bir gıda sisteminin olumsuz etkilerine giderek daha fazla farkına varmaktadır ve çiftçilerle yeniden doğrudan bir bağlantı kurmaya, yerel toplulukları desteklemeye, sağlıklı gıda tüketmeye isteklidirler (Duram ve Cawley, 2012). Ayrıca, küresel gıda talebinin 2030 yılına kadar \%50 artacağı tahmin ediliyor ve bu da üretim ve ulaşım için kaynak talebinin artmasına yol açıyor (Allaoui vd., 2018). Planlayıcılar, paydaşlar ve araştırmacılar, gelecekte yeterince sağlıklı gıdaya ulaşıp ulaşamayacağımızı ve ne pahasına olacağını merak ediyorlar. 
Bu sebeple, özellikle gıda tedarik zincirleri (GTZ)'de firmaların, müşteri beklentilerini karşılamak için rakiplerinden daha hızlı ve daha esnek olmasının yanı sıra sürdürülebilir paradigmaları uygulamaları da gerekmektedir. Tüm bu koşullar göz önünde alındığı zaman GTZ' de hammaddelerin çiftçilerden doğrudan alınarak, aracılardan ortadan kalkmasıyla hem üreticiler hem de çiftçiler ekonomik fayda sağlamış olacaktır. Çiftçiden direk alınmış taze ve doğal hammaddeler sayesinde, ürünlerin insan sağlı̆̆ına olan zararlarında azalma sağlanacaktır. Son müşteriden kullanılmış ürünler geri toplanarak, atıkların çevreye zarar vermesi önlenmiş hem de ürünlerin geri dönüşümü ile ekonomik fayda sağlanmış olacaktır.

Son yıllardaki değişimler ve gelişmeler ışığında, sürdürülebilir paradigmalar GTZ ağ tasarımı için büyük önem arz etmektedir. Bu kapsamda, bu çalışmada gıda sektöründe faaliyet gösteren bir meyve suyu firmasının TZ ağ tasarımı oluşturulmuştur. Çiftçiden satın alınan şeftalilerin, son müşteriye cam şişede meyve suyu olarak ulaşana kadar ki ve son müşterideki kullanılmış ürünlerin geri dönüşümüne kadar geçen tüm süreçler için GTZ ağ tasarımı yapılmıştır.

\section{Kavramsal Çerçeve}

Bu bölümde GTZ ağ tasarımına ilişkin kapsamlı bir literatür taramasına yer verilmiştir. Eleştirel bir bakış açısı sağlamak amacıyla Tablo 1'de literatür matrisi oluşturulmuştur.

Apaiah ve Hendrix (2005), Hollanda'daki yeni proteinli gıdaların tedarik ağını optimize eden doğrusal bir model önermiştir. Gong vd. (2007), taze tarımsal ürünlerin toplam envanter taşıma maliyetini ve TZ' deki atıkları en aza indirmek için, GTZ ağ tasarımı için bir envanter konum tahsis modeli geliştirmiştir. Çözümün kalitesini artırmak için, bir yerel arama Parçacık Sürüsü Optimizasyonu (PSO) algoritmasına yerleştirilmiştir. Sonuçlar, algoritmanın farklı maliyetler arasındaki çatışmayı etkili bir şekilde çözebileceğini ve Pekin'in çabuk bozulan gıda dağıtım merkezleriyle ilgili geliştirme kararlarını iyileştirebileceğini göstermektedir. Jiang vd. (2009), bir et-gıda TZ'de tedarik kesintileri meydana geldikten sonra TZ ağının hayatta kalma ve dayanıklılı̆̆ını arttırmak için çoklu tedarikçiye dayalı esnek bir ağ tasarımı için karışık tam sayılı stokastik bir model geliştirmiştir. Önerilen modeli çözmek için Benders ayrıştırma algoritması kullanılmıştır. Modelin uygulanabilirliği ve doğruluğu için vaka çalışması yapılmıştır. Akkerman vd. (2010), gıda dağıtım yönetimine yönelik nicel operasyon yönetimi yaklaşımlarını ve sektörün karşılaştı̆̆ gıda dağıtım yönetimiyle ilgili zorlukları araştırmıştır. Literatürün gıda kalitesi, gıda güvenliği ve sürdürülebilirlik olmak üzere üç yönüne, üç karar seviyesinde odaklanılmıştır: stratejik ağ tasarımı, taktik ağ planlaması ve operasyonel ulaşım planlaması. Zhao ve Lv (2011), tarımsal GTZ'de tesis konumu ve üretim kapasitesi seçimini işlemek için karma tamsayı model geliştirmiştir. Çok kademeli ve çok ürünlü TZ için tasarım probleminin karmaşıklığından dolayı, PSO algoritması önerilmiştir. Hasani vd. (2012), aralıklı veri belirsizliği altında stratejik KDTZ ağı tasarımı için genel kapsamlı bir model önermiştir. Ogier vd. (2013), tedarikin mevsimselliği, ürünler için aktarmaların sınırlandırılması ve ardışık dönemler arasında depolama imkânı olmaması sebebiyle taze GTZ ağ tasarımı için karma tam sayılı model geliştirmiştir. Govindan vd. (2014), sürdürülebilirliği, bozulabilir bir GTZ ağında dağıtım konusunda karar verme sürecine entegre ederek çok amaçlı bir optimizasyon modeli 
önermiştir. Sürdürülebilir TZ ağ tasarımı ve bozulabilir bir gıda TZ'de ekonomik ve çevresel hedefleri optimize etmek için zaman pencereli iki kademeli konum yönlendirme problemi kullanılmıştır. Soysal vd. (2014), genel bir sığır lojistik ağı probleminde toplam lojistik maliyetini en aza indirmek ve nakliye operasyonlarından kaynaklanan toplam sera gazı emisyonu miktarını en aza indirmek için çok amaçlı bir doğrusal programlama modeli geliştirmiştir. Validi vd. (2014), İrlanda'da sütün dağıtımında yer alan iki katmanlı bir TZ için kapasiteli bir dağıtım ağının tasarımına yönelik sağlam bir çözüm yaklaşımı önermiştir. Cascini vd. (2014), taze GTZ' de hem küresel maliyeti hem de çevresel etkiyi en aza indirgemek için çok amaçlı, çok ürünlü, çok katmanlı, çok dönemli bir karmaşık tam sayılı doğrusal model geliştirmiştir. Önerilen modelin uygulanabilirliği ve doğruluğu için bir GTZ ağ tasarımı vaka çalışması ile gösterilmiştir. TZ ağlarında hasat sonrası kaybı (PHL) azaltmak için, Nourbakhsh vd. (2016), yeni ön işleme tesisleri için en uygun yerleri belirleyerek ve karayolu / demiryolu kapasite genişlemesini optimize ederek tahıl nakliyesi ve altyapı yatırımı için optimum lojistiği belirleyen bir matematiksel model önermiştir. Marco Bortolini vd. (2016), işletim maliyeti, karbon ayak izi ve teslimat süresi hedefleri göz önünde bulundurularak taze gıda dağıtım ağlarının taktiksel optimizasyonunun üstesinden gelmek için üç hedefli bir TZ ağı önermiştir. Uygulanabilirliği doğrulamak için bir dizi İtalyan üreticiden birkaç Avrupalı perakendeciye taze meyve ve sebzelerin dağıtımını ele alan gerçek bir vaka çalışması kullanılmıştır. Colicchia vd. (2016), hem verimli hem de ekolojik olarak sağlam olan bir TZ ağı tasarımı için çok amaçlı matematiksel model geliştirilmiştir. Önerilen modelin uygulanabilirliği ve doğruluğu için Lindt \& Sprüngli firmasının çikolata ürünlerinin dağıtımı vaka çalışması ile gösterilmiştir. Sonuçlar, maliyet odaklı ağ optimizasyonunun çevre için yararlı etkilere yol açabileceğini ve dağıtım maliyetlerindeki küçük bir artışın, çevresel performanstaki büyük bir iyileştirmeyle dengelenebileceğini göstermektedir. Mohammed vd. (2017a), ilk olarak helal et ürünlerinin bütünlüğünün izlenebilirliğini artırmak için önerilen bir RFID tabanlı yönetim sistemi tarafından izlenen üç kademeli bir helal et tedarik zinciri (HMSC) ağının ekonomik fizibilitesini araştırmak için deterministik çok amaçlı karışık tamsayı doğrusal programlama modeli geliştirmiş ve önerilen RFID tabanlı HMSC ağını, şu hedeflere dayalı olarak optimize etmek için kullanmıştır; 1- Helal et ürünlerinin ortalama bütünlük sayısını en üst düzeye çıkarmak, 2- yatırım getirisini (ROI) en üst düzeye çıkarmak, 3tesislerin kapasite kullanımını en üst düzeye çıkarmak ve 4- önerilen RFID izleme sisteminin toplam yatırım maliyetini en aza indirmek. İkinci olarak, bütünlük yüzdesinin değerini değiştirerek Helal et ürünlerinin sayısı üzerindeki etkisini incelemek için bir stokastik programlama modeli geliştirmiştir. Geliştirilen modellerin gerçek bir vaka çalışması kullanılarak uygulanabilirliğini gösterilmiştir. Mohammed ve Wang (2017), toplam nakliye maliyetini, nakliye araçlarının sayısını ve et ürünlerinin teslim süresini en aza indirmeyi amaçlayan uygun maliyetli et TZ ağ tasarımı için çok amaçlı olasılıklı bir model geliştirmiştir. Geliştirilen çok amaçlı modelin ve önerilen çözüm yöntemlerinin etkililiği ve uygulanabilirliği bir vaka çalışmasıyla gösterilmiştir. Mohammed vd. (2017b), helal et ürünlerinin bütünlüğünün izlenebilirliğini artırmak için bir Helal et TZ ağı tasarımı için RFID özellikli bir izleme sistemi geliştirmiştir. Önerilen RFID destekli izleme sisteminin ekonomik fizibilitesini araştırmak için çok amaçlı bir model geliştirmiştir. Geliştirilen matematiksel modelin uygulanabilirliği ve doğruluğu için bir vaka çalışması 
yapılmıştır. Miranda-Ackerman vd. (2017), tedarikçi, üretim ve pazar seviyelerinden oluşan üç aşamalı bir yeşil TZ ağının çok amaçlı optimizasyonu modellemiştir. Modelin uygulanabilirliği ve doğruluğu bir portakal suyu TZ vaka çalışmasıyla gösterilmiştir. Mohammed vd. (2017c), toplam uygulama ve operasyon maliyetinin en aza indirilmesi ve müşteri memnuniyetinin ve ürün kalitesinin en üst düzeye çıarılması açısından bir et TZ ağı için uygun maliyetli bir ağ tasarımı elde etmeyi amaçlayan çok kriterli optimizasyon modeli geliştirmiş̧ir. Modelin uygulanabilirliğini ve önerilen çözüm yaklaşımlarının performansını incelemek için bir vaka çalışması yapılmıştır. Gholamian ve Taghanzadeh (2017), uzun vadeli tedarikçi seçimi kararlarını, yeni siloları yerleştirmeyi, buğdayın ve ürünlerinin orta vadeli atama ve dağıtım kararlarını içeren entegre buğday ürünleri TZ ağ tasarımı için bir model geliştirmiştir. Allaoui vd. (2018), ilk aşamada Analitik Hiyerarşi Süreci (AHP) yöntemine ve Sıralı Ağırlıkı Ortalama (OWA) toplama yöntemine dayalı melez çok kriterli karar verme yöntemi kullanarak paydaş seçimi yapmıştır, ikinci aşamada TZ'yi optimize etmek için ilk aşamada elde edilen sonuçları kullanarak çok amaçlı bir matematiksel model geliştirmiştir. Modelin uygulanabilirliğini ve verimliliğini bir tarım-gıda şirketinin vakası ile gösterilmiştir. M. Bortolini vd. (2018), sürdürülebilirliği artırmak amacıyla tek kullanımlık ve yeniden kullanılabilir olmak üzere iki farklı paketleme kabı kullanmıştır. Bu ambalaj kaplarının maliyetleri ve emisyonları doğal olarak farlıdır. Paketleme kabı en iyi seçimi, depolama / işleme düğüm lokasyonu ve akış dağıtımını belirlemek amacıyla taze meyve ve sebze dağıtımı zinciri ağ tasarımı için çift amaçlı karışık tam sayılı doğrusal programlama modeli geliştirmiştir. Modelin uygulanabilirliği İtalya'nın Emilia-Romogna bölgesinden gerçek bir vaka ile gösterilmiştir. Barsing vd. (2018), GTZ'de kısa raf ömrü ve yüksek çeşitlilik sebebiyle oluşan belirsizlik, öngörülemezlik ve karmaşıklık seviyesini azaltmak ve ortadan kaldırmak için çapraz yerleştirme merkezi kullanmıştır. Paydaşlar arasında malzeme veya bilgi akışına dayanarak $\mathrm{n}$ tane çapraz yerleştirme tesisinden birini seçmek için yeni bir yaklaşım geliştirmiştir. Das (2019), önemli miktarda atık ve emisyon üreten mevcut GTZ uygulamalarının sınırlarının üstesinden gelmek ve performanslarını iyileştirmek için esneklik kriterlerini, yalın ve yeşil tabanlı uygulamaları bütünleştiren sürdürülebilir bir GTZ ağı tasarım modeli geliştirmiştir. Modelin uygulanabilirliği örnek bir eyaletin şebeke ağı ile gösterilmiştir. Rohmer vd. (2019), küresel GTZ bağlamında sürdürülebilirlik konularını ele alan yeni bir ağ tasarımı geliştirmiştir. Alternatif üretim ve tüketim senaryolarının yanı sıra birbirleriyle çelişen hedefler arasındaki ödünleşmeleri, beslenmeyle ilgili bir vaka çalışmasıyla göstermiştir. Darestani ve Hemmati (2019), bozulmalarla ilgili belirsizlikleri dikkate alırken, çabuk bozulan mallar için bir TZ ağı modeli önermiştir. Önerilen model toplam şebeke maliyetlerini en aza indirmek ve sera gazı emisyonlarını en aza indirmek üzere iki alt amaç içermektedir. İki amaçlı modeli çözmek için genel ağılıklandırma yöntemi ve Torabi-Hassini yöntemi kullanılmıştır. Ghanbari ve Bashiri (2019), esnek tarımsal GTZ tasarlamak için hem tedarikçiler hem de dağıtım merkezleri için kesinti senaryolarını dikkate alan iki aşamalı stokastik model geliştirmiştir. Yıkıcı olaylara rağmen hızlı tepki verebilmek için şu üç stratejiyle esnek bir model oluşturmuştur; 1Yedekleme tesisini tedarikçilere ve dağıtım merkezlerine ayırmak, 2- tedarikçiler ve dağıtım merkezlerinde çoklu kaynak kullanımı, 3- Tedarikçiler için kesinti olasıllı̆ğın azaltmak için azaltma stratejileri. Sonuçlar, TZ için esnek stratejilerin uygulanmasının 
daha fazla kar elde edeceğini ve maliyetlerden tasarruf sağlayacağını kanıtlamıştır. Pourmohammadi vd., (2020), İran'da buğday TZ'nin yeniden tasarlanması ve planlanması için uzun vadeli ve kısa vadeli depolama tesisleri ile buğday kalitesi arasındaki farkları dikkate alan karma tam sayılı doğrusal matematiksel bir model geliştirmiştir. Mohammadi vd. (2020), işlenmiş gıda endüstrisindeki TZ'yi sabit raf ömürlü ürünlerle tasarlamak için çok amaçlı bir model önermiştir. Ekonomik bir endeks olarak kâr maksimizasyonu ile ekonomik, imalat sektöründe karbondioksit emisyonları ve atık su arıtma endeksi ile çevresel ve sosyal bir endeks olarak yaratılan iş sayısını en üst düzeye çıkarma modelin hedefleri arasında bulunmaktadır. Biuki vd. (2020), sürdürülebilirliğin üç boyutunu TZ uygulamalarına dâhil etmek için iki aşamalı bir yaklaşım önermiştir. İlk aşamada, sürdürülebilir bir TZ'nin planlanmasına yardımcı olmak için çok amaçlı bir Karışık Tam Sayı Programlama modeli tasarlamıştır. İkinci aşamada, problemi çözmek için Genetik Algoritma (GA) ve PSO algoritması paralel ve seri kombinasyonları olarak iki melez metasezgisel yöntem kullanılmıştır. Mogale vd. (2020), sürdürülebilir gıda tahıl TZ için iki taraflı, maliyeti ve karbondioksit emisyonunu aynı anda en aza indirmeyi amaçlayan karar destek modeli geliştirmiştir. Model, çok kademeli, çok dönemli, çok modlu taşımacılık, çoklu kaynak bulma ve dağıtım, çeşitli nedenlerden kaynaklanan emisyonlar, heterojen kapasiteli araçlar ve sınırlı kullanılabilirlik ve kapasiteli depolar gibi birçok sorun özelliğini kapsamaktadır. Jouzdani ve Govindan (2021), bozulabilir gıda ürünleri TZ'de maliyet, enerji tüketimi ve trafik sıkışıklığını optimize etmek için sürdürülebilirliğin TBL yaklaşımını dikkate alarak çok amaçlı bir matematiksel model geliştirmiştir. Ürün ömür belirsizliği bir Weibull rastgele değişkeni olarak modellenmiş ve gıda bozulabilirliğinin bir karar değişkeni olarak kabul edilen araç buzdolabı kullanımından etkilendiği varsayılmıştır. Çalışmada \%15'lik bir ekonomik uzlaşma, tedarik zinciri ağ1 tasarımının sürdürülebilirliğini \%150 oranında artırabilir sonucuna varılmıştır.

\section{Yöntem ve Model Çerçevesi}

Bu çalışmada şeftali suyu üretimi üzerine bir sürdürülebilir kapalı döngü tarım gıda tedarik zinciri ağı yapısı incelenmiştir. İşlenmişşşeftali ürünlerinin tedarik zinciri sisteminde, çiftçiler ana hammadde tedarikçileridir. Çiftçilere ek olarak, üreticiler bazen hammaddeleri büyük tüccarlardan ( 2. Kademe Tedarikçiler) da temin etmektedir. $\mathrm{Bu}$ durumda, doğrudan çiftçilerden hammadde alınmaması nedeniyle tedarik zinciri daha uzun olabilmektedir. Distribütörler, şeftali suyunu üreticiden perakendecilere veya tüketicilere dağıtır. Perakendeciler, üreticilerin şeftali suyu ürünlerini pazarlamak için en çok tercih ettikleri alternatiftir. Şeftali suyu tüketicileri, farklı bölgelerde yaşayan yerel tüketicilerden oluşmaktadır.

Şeftali suyu tedarik zinciri konfigürasyonu Şekil 1>de sunulmuştur. Firma, haziran, temmuz ve ağustos aylarında çiftçiler veya 2. kademe tedarikçilerden temin ettiği şeftalileri üretim merkezinde işleyerek şeftali suyu nihai ürünü şeklinde dağıtım ve toplama merkezine oradan da müşterisi konumundaki perakendecilere ulaştırır. Elde ettiği nihai ürünlerin ambalaj ve paketlenmesi için cam şişe tedarikçisi ve ambalaj tesisleri ile işbirliği içerisinde olan firma, ayrıca üretim aşamasında ortaya çıkan posayı organik gübreye dönüştürmek üzere satarak ve müşterilerden kullanılmış cam şişeleri belli oranda geri toplayarak da 
çevreye duyarlı sürdürülebilir tarım gıda sektörüne uygun üretim yapmaktadır. Toplanan cam şişelerden uygun olanlar dezenfekte edilip üretim merkezinde yeniden kullanılırken kalan kısım ise yeniden işlenmek üzere geri dönüşüm merkezine oradan da tekrar cam şişe tedarikçisine satılmaktadır.

Tablo 1. Tarım-Gıda Tedarik Zinciri Literatür Matrisi

\begin{tabular}{|c|c|c|c|c|c|}
\hline Yazar & $\begin{array}{c}\text { Geleneksel } \\
\text { Ă̆ Tasarımı }\end{array}$ & $\begin{array}{c}\text { Kapalı Döngü } \\
\text { Ăg Tasarımı }\end{array}$ & Sürdürrülebilirlik & Gıda Türü & Çözüm Yöntemi \\
\hline Apaiah ve Hendrix (2005) & $\checkmark$ & & & Proteinli G1da & LP \\
\hline Gong vd. (2007) & $\checkmark$ & & & Bozulabilir G1da & PSO \\
\hline Jiang vd. (2009) & $\checkmark$ & & & Et & MISP \\
\hline Zhao ve Lv (2011) & $\checkmark$ & & & Elma & PSO \\
\hline Hasani vd. (2012) & & $\checkmark$ & & Bozulabilir Gıda & MILP \\
\hline Ogier vd. (2013) & $\checkmark$ & & & Taze Gıda & $\mathrm{BD}, \mathrm{DSSP}$ \\
\hline Govindan vd. (2014) & & $\checkmark$ & $\checkmark$ & Bozulabilir Gıda & MOPSO, AMOVNS \\
\hline Soysal vd. (2014) & & $\checkmark$ & $\checkmark$ & Et & MOLP \\
\hline Validi vd. (2014) & $\checkmark$ & & $\checkmark$ & Mandıra & $\begin{array}{l}\text { TOPSIS, MOGA-II, } \\
\text { NSGA-II }\end{array}$ \\
\hline Cascini vd. (2014) & & $\checkmark$ & & Sebze & MILP \\
\hline Nourbakhsh vd. (2016) & $\checkmark$ & & & Tahil & MILP \\
\hline Bortolini vd. (2016) & $\checkmark$ & & $\checkmark$ & Taze Gida & TOLP \\
\hline Colicchia vd. (2016) & $\checkmark$ & & & Çikolata & MOMP \\
\hline Mohammed vd. (2017a) & $\checkmark$ & & & Helal Et & MOMILP \\
\hline Mohammed ve Wang (2017) & $\checkmark$ & & & Et & MOPP \\
\hline Mohammed vd. (2017b) & $\checkmark$ & & & Helal Gida & POS \\
\hline Miranda-Ackerman vd. (2017) & $\checkmark$ & & $\checkmark$ & $\begin{array}{c}\text { Portakal Meyve } \\
\text { Suyu }\end{array}$ & LCA, GA, TOPSIS \\
\hline Mohammed vd. (2017c) & $\checkmark$ & & & Et & $\mathrm{MCOM}$ \\
\hline Gholamian ve Taghanzadeh (2017) & $\checkmark$ & & & Buğday & MILP \\
\hline Allaoui vd. (2018) & $\checkmark$ & & $\checkmark$ & Genel Gida & HDMM, MOMP \\
\hline Bortolini vd. (2018) & & $\checkmark$ & & Taze Gida & BOMILP \\
\hline Barsing vd. (2018) & $\checkmark$ & & & Hazır Yemek & SNA \\
\hline Das (2019) & $\checkmark$ & & $\checkmark$ & Genel Gida & $\begin{array}{l}\text { Mathematical } \\
\text { Programming }\end{array}$ \\
\hline Rohmer vd. (2019) & $\checkmark$ & & $\checkmark$ & Besleyici Gıda & MOLP \\
\hline Darestani ve Hemmati (2019) & & $\checkmark$ & & Bozulabilir Gıda & CCM, WSM, THM \\
\hline Ghanbari ve Bashiri (2019) & $\checkmark$ & & & Genel Gida & TSSP \\
\hline Pourmohammadi vd. (2020) & $\checkmark$ & & & Buğday & SBSP \\
\hline Mohammadi vd. (2020) & $\checkmark$ & & $\checkmark$ & Genel Gida & AUGMECON \\
\hline Biuki vd. (2020) & $\checkmark$ & & $\checkmark$ & Bozulabilir G1da & PSO, GA \\
\hline Mogale vd. (2020) & $\checkmark$ & & & Tah1l & MOPSO, NSGA-II \\
\hline Jouzdani ve Govindan (2021) & $\checkmark$ & & $\checkmark$ & Bozulabilir Gida & RMCGP \\
\hline Bu Çalışma & & $\checkmark$ & $\checkmark$ & $\begin{array}{c}\text { Şeftali Meyve } \\
\text { Suyu }\end{array}$ & MILP \\
\hline
\end{tabular}

LP: Linear Programming, PSO: Particle Swarm Optimization, MISP: Mixed Integer Stochastic Programming, MILP: Mixed Integer Linear Programming, MOPSO: Multi-Objective Particle Swarm Optimization, AMOVNS: Adapted Multi-Objective Variable Neighborhood Search, MOLP: Multi-Objective Linear Programming, BD: Benders Decomposition, DSSP: Dynamic Slope Scaling Procedure, TOPSIS, MOGA-II: Multi-Objective GA of kind II, NSGA-II: Non-Dominated Sorting GA of kind II, TOLP: Three Objective Linear Programming, MOMP: MultiObjective Mathematical Programming, MOMILP: Multi-Objective Mixed Integer Linear Programming, MOPP: Multi-Objective Possibilistic Programming, POS: Pareto Optimal Solution, LCA: Life Cycle Assessment, GA: Genetic Algorithm, MCOM: Multi-Criteria Optimization Method, HDMM: Hybrid Decision-Making Method, BOMILP: Bi-Objective Mixed Integer Linear Programming, SNA: Social Network Analysis, CCM: Comprehensive Criteria Method, WSM: Weighted Sum Method, THM: Torabi-Hassini Method, TSSP: Two-Stage Stochastic Programming, SBSP: Scenario-based Stochastic Programming, AUGMECON, RMCGP: Revised Multi-Choice Goal Programming 


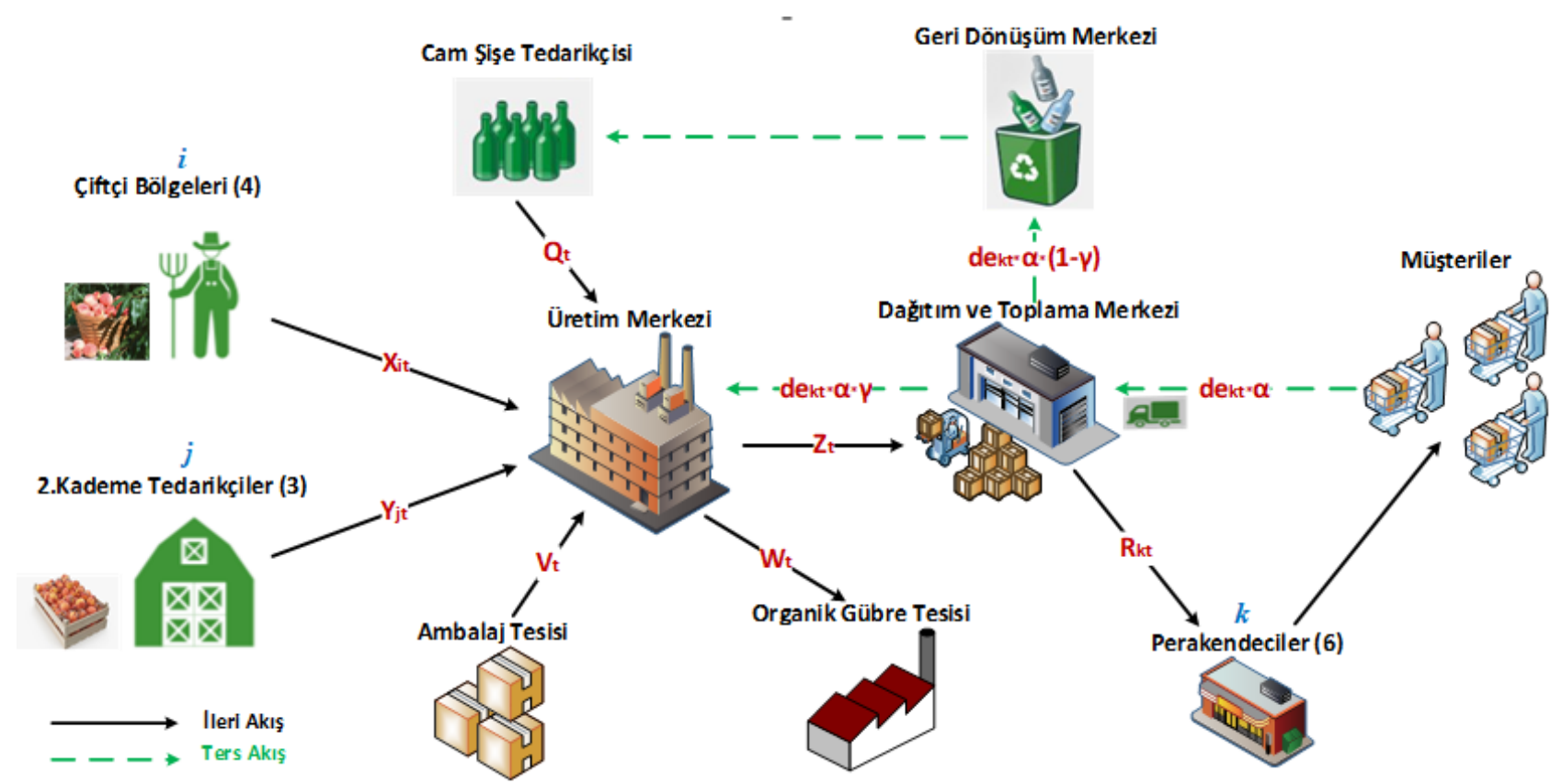

Şekil 1. Şeftali Suyu Üretimi için Temsili Kapalı Döngü Tarım-Gıda Tedarik Zinciri Ağı

\section{Probleme ilişkin bazı varsayımlar:}

1) Tek tip bir nihai ürün (1 lt'lik şeftali suyu) üretilmektedir.

2) Yeni bir cam şişe ile yıkanıp dezenfekte edilen veya geri dönüştürülen bir cam şişe arasında hiçbir fark yoktur.

3) Üretim kapasitesi tüm nihai ürün gereksinimi için yeterlidir.

4) Tüm maliyet ve satış fiyatı bilgileri bilinmektedir.

5) Her bir dönem için müşterilerin (perakendeciler) talebi kesin olup tümüyle karşılanmaktadır.

6) Yok satma olmadığg varsayılmıştır.

\subsection{Matematiksel Model}

Model, yukarıdaki varsayımlara dayanarak talebi karşılamak üzere kârı en büyüklemeye çalışmaktadır.

\section{Indisler}

$\boldsymbol{i}$ : Çiftçi Bölgeleri $(i=1,2, \ldots, I)$

$\boldsymbol{j}:$ 2. Kademe Tedarikçiler $(j=1,2, \ldots, J)$

$\boldsymbol{k}:$ Perakendeciler $(k=1,2, \ldots, K)$

$\boldsymbol{t}:$ Periyot $(t=1,2, \ldots, T)$ 


\section{Parametreler}

$p c_{i t}:$ i. çiftçi bölgesinden t periyodunda şeftali satın alma maliyeti (‡)

$\boldsymbol{p t}_{\boldsymbol{j} \boldsymbol{t}}: j$. 2. kademe tedarikçisinden t periyodunda şeftali satın alma maliyeti(‡)

$\boldsymbol{d c}_{\boldsymbol{i}}:$ i. çiftçi bölgesi ile üretim merkezi arasındaki mesafe $(\mathrm{km})$

$\boldsymbol{d t}_{\boldsymbol{j}}: j$. 2. kademe tedarikçisi ile üretim merkezi arasındaki mesafe(km)

$\boldsymbol{d d}$ : Üretim merkezi ile dağıtım ve toplama merkezi arasındaki mesafe $(\mathrm{km})$

$\boldsymbol{d p}_{\boldsymbol{k}}$ : Dağıtım ve toplama merkezi ile $\mathrm{k}$. perakendeci arasındaki mesafe (km)

$\boldsymbol{C} \boldsymbol{c}_{\boldsymbol{i}}:$ i. çiftçi bölgesinin şeftali üretim kapasitesi(ton)

$\boldsymbol{C t}_{\boldsymbol{j}}:$ j. 2. kademe tedarikçinin şeftali üretim kapasitesi(ton)

$\boldsymbol{d e}_{\boldsymbol{k} t}: k$. perakendecinin(müşsterinin) $t$ dönemindeki şeftali suyu talebi(lt)

$\boldsymbol{a}:$ Üretim merkezinin şeftali işleme maliyeti (‡/ton)

sa : Bir koli şeftali suyu satış fiyatı(‡/glt)

$\boldsymbol{s b}:$ Organik gübre tesisine şeftali posası satış fiyatı(‡/ton)

sc : Geri dönüşüm merkezine kullanılmış cam şişe satış fiyatı(‡/adet)

ta : Birim şeftali taşıma maliyeti (ton)

tb : Birim şeftali suyu taşıma maliyeti (lt)

ps : Cam şişe tedarikçisinden 1 litrelik cam şişe satın alma maliyeti (‡/adet)

pk : Ambalaj tesisinden karton kutu satın alma maliyeti (‡/adet)

$\boldsymbol{\alpha}:$ Müşterilerden dağltım ve toplama merkezine geri dönen cam şişe yüzdesi (\%)

$\boldsymbol{\beta}$ :İşlenmişs şeftaliden açığa çıkan posa yüzdesi (\%)

$\gamma$ :Yeniden kullanılacak cam şişe yüzdesi (\%)

$\boldsymbol{g}$ :Karton kutu hacmi (alabildiği 1 lt'lik şişe sayısı)

$f: 1$ lt şeftali suyunun ăgırliğı (ton)

$\boldsymbol{h}:$ Şeftali suyunun stok maliyeti (£/lt)

\section{Karar Değişkenleri}

$\boldsymbol{X}_{i t}$ : t periyodunda i çiftçisinden üretim merkezine taşınan şeftali miktarı (ton)

$\boldsymbol{Y}_{j t}$ : t periyodundaj 2. kademe tedarikçidem üretim merkezine taşınan şeftali miktarı (ton)

$Z_{t}: t$ periyodunda üretim merkezinden dağıtım ve toplama merkezine taşınan şeftali suyu miktarl (lt) 
$\boldsymbol{Q}_{t}$ : t periyodunda cam şişe tedarikçisinden üretim merkezine gelen cam şişe miktarı (adet)

$\boldsymbol{V}_{\boldsymbol{t}}:$ t periyodunda ambalaj tesisinden üretim merkezine gelen karton kutu miktarı (adet)

$\boldsymbol{W}_{t}:$ t periyodunda üretim merkezinden organik gübre tesisine gönderilen şeftali posası miktarl (ton)

$\boldsymbol{R}_{\boldsymbol{k} t}:$ t periyodunda dağıttım ve toplama merkezinden k perakendecisine gönderilen şeftali suyu miktarl (lt)

$\boldsymbol{I}_{\boldsymbol{t}}:$ t periyodunda dağıtım ve toplama merkezinde bulunan şeftali suyu stok miktarı (lt)

\section{Amaç Fonksiyonları}

Amaç fonksiyonu, toplam kârı maksimize etmektir. Yani model, toplam geliri maksimize ederken toplam maliyeti minimize eder. Bu nedenle amaç fonksiyonu toplam gelirin (TG), toplam maliyete (TM) olan farkı şeklinde hesaplanmaktadır. İki kısımdan oluşan amaç fonksiyonu aşağıdaki gibidir:

$\mathrm{Z}=\mathrm{TG}-\mathrm{TM}$

1) Toplam Gelir (TG): Firma, şeftali suyu nihai ürünü başta olmak üzere, şeftali posası ve geri dönüştürülecek cam şişe satışı gerçekleştirmektedir. Bu yüzden TG aşağıdaki gibi üç kısımdan oluşmaktadır.

$\mathrm{TG}=\sum_{k} \sum_{t} \mathrm{R}_{k t} \cdot\left(\frac{\mathrm{sa}}{\mathrm{g}}\right)+\sum_{t} \mathrm{~W}_{t} \cdot \mathrm{sb}+\sum_{k} \sum_{t} \mathrm{de}_{k t} \cdot \alpha \cdot(1-\gamma) \cdot s c$

2) Toplam Maliyet (TM): Firma, toplam satın alma maliyeti (TSM), toplam üretim maliyeti (TÜM), toplam taşıma maliyeti (TTM) ve şeftali suyu stok maliyeti (SM) olmak üzere dört farklı maliyete katlanmaktadır. Bu yüzden TM aşağıdaki gibi formülize edilmiştir.

$\mathrm{TM}=\mathrm{TSM}+\mathrm{TÜM}+\mathrm{TTM}+\mathrm{SM}$

2.1) Toplam satın alma maliyeti (TSM): TSM'nin ilk kısmı, üretim merkezinin şeftali talebini karşılamak üzere çiftçilerden ve 2 . kademe tedarikçilerinden yapılan satın alma maliyetlerini, ikinci kısım şeftali sularını ambalajlamak için kullanılan cam şişe satın alma maliyetini ve üçüncü kısımda cam şişeleri paketlemek üzere kullanılan karton kutu satın alma maliyetini göstermektedir.

$\mathrm{TSM}=\left(\sum_{\mathrm{i}} \sum_{\mathrm{t}} \mathrm{X}_{\mathrm{it}} \cdot \mathrm{pc}_{\mathrm{it}}+\sum_{\mathrm{j}} \sum_{\mathrm{t}} \mathrm{Y}_{\mathrm{jt}} \cdot \mathrm{pt}_{\mathrm{jt}}\right)+\left(\sum_{\mathrm{t}} \mathrm{Q}_{\mathrm{t}} \cdot p s\right)+\left(\sum_{\mathrm{t}} \mathrm{V}_{\mathrm{t}} \cdot p k\right)$

2.2) Toplam üretim maliyeti (TÜM): Üretim maliyeti; fabrikada şeftalinin işlenmesi için tüketilen kaynakların (elektrik, su, makine, işçilik vb.) toplam maliyetleri hesaplanarak tek kalem şeklinde (a) aşağıdaki gibi hesaplanmıştır.

$\mathrm{TÜM}=a \cdot\left(\sum_{\mathrm{i}} \sum_{\mathrm{t}} \mathrm{X}_{\mathrm{it}}+\sum_{\mathrm{j}} \sum_{\mathrm{t}} \mathrm{Y}_{\mathrm{jt}}\right)$

2.3) Toplam taşıma maliyeti (TTM): Modelde taşıma hammadde ve nihai ürün bazında ele alınmıştır. Çiftçilerden ve 2 . kademe tedarikçilerinden üretim merkezine yapılan şeftali (hammadde) birim taşıma maliyetleri (ta) eşit kabul edilmiştir. Ayrıca, üretim merkezinden 
dağıtım ve toplama merkezine ve dağıtım ve toplama merkezinden perakendecilere olan şeftali suyu (nihai ürün) taşıma maliyetlerinin (tb) de eşit olduğu kabul edilmiştir. Buna göre toplam taşıma maliyeti aşağıdaki gibi hesaplanmaktadır.

$\mathrm{TTM}=t a \cdot\left(\sum_{\mathrm{i}} \sum_{\mathrm{t}} \mathrm{X}_{\mathrm{it}} \cdot \mathrm{dc}_{\mathrm{i}}+\sum_{\mathrm{j}} \sum_{\mathrm{t}} \mathrm{Y}_{\mathrm{jt}} \cdot \mathrm{dt}_{\mathrm{j}}\right)+t b \cdot\left(\sum_{\mathrm{t}} \mathrm{Z}_{\mathrm{t}} \cdot d d+\sum_{\mathrm{k}} \sum_{\mathrm{t}} \mathrm{R}_{\mathrm{kt}} \cdot \mathrm{dp}_{\mathrm{k}}\right)$

2.4) Stok maliyeti (SM): Fabrikada üretilen şeftali sularının tümü dağıtım ve toplama merkezine gönderilmektedir. Buradaki şeftali suları talep miktarınca perakendecilere iletilirken, kalan kısım ise sonraki dönemlerde satılmak üzere stoklanır ve maliyeti aşağıdaki gibi hesaplanır.

$\mathrm{SM}=\sum_{t} I_{t} \cdot h$

\section{Kisitlar}

$$
\begin{array}{ll}
\left(\sum_{\mathrm{i}} \mathrm{X}_{\mathrm{it}}+\sum_{\mathrm{j}} \mathrm{Y}_{\mathrm{jt}}\right)-\left(\mathrm{Z}_{\mathrm{t}} \cdot f+\mathrm{W}_{\mathrm{t}}\right)=0, & \forall t \\
\mathrm{Z}_{\mathrm{t}}-\left(\mathrm{Q}_{\mathrm{t}}+\sum_{\mathrm{k}} \mathrm{de}_{\mathrm{k}(\mathrm{t}-1)} \cdot \alpha \cdot \gamma\right)=0, & \forall t \\
\frac{\left(\mathrm{Q}_{\mathrm{t}}+\sum_{\mathrm{k}} \mathrm{d} \mathrm{e}_{\mathrm{k}(\mathrm{t}-1)} \cdot \alpha \cdot \gamma\right)}{g}-V_{t}=0, & \forall t \\
\beta \cdot\left(\sum_{\mathrm{i}} \mathrm{X}_{\mathrm{it}}+\sum_{\mathrm{j}} \mathrm{Y}_{\mathrm{jt}}\right)-\left(\mathrm{W}_{\mathrm{t}}\right)=0, & \forall t \\
\left(Z_{t}+I_{t-1}\right)-\left(\sum_{k} \mathrm{R}_{k t}+I_{t}\right)=0, & \forall t \\
\mathrm{R}_{k t}=d e_{k t}, & \forall k, t \\
\mathrm{X}_{i t} \leq C c_{i}, & \forall i, t \\
\mathrm{Y}_{j t} \leq C t_{j}, & \forall j, t \\
X_{i t}, Y_{j t}, W_{t} \geq 0, & \forall i, j, t \\
Z_{t}, Q_{t}, V_{t}, R_{k t}, I_{t} \geq 0, \text { tamsayı } & \forall k, t
\end{array}
$$

Kısıt (8)-(12)-Denge Kısıtlarıdır-İlki, üretim merkezine gelen şeftali miktarının, çıkan şeftali suyu ve posası miktarına eşit olmasını sağlar; ikincisi, yine üretim merkezine gelen şişe miktarının üretilen şeftali suyunu şişelemek için gerekli olan şişe miktarı kadar olmalıdır. Yani gelen şişe miktarı üretim merkezinden dağıtım ve toplama merkezine gönderilen nihai ürün şişe ihtiyacını karşılamalıdır; üçüncüsü, satın alınacak karton kutu miktarını belirler, üretim merkezine gelen şişe miktarı karton kutu hacmine $(g)$ bölünerek paketleme için gerekli olan karton kutu miktarı bulunur; dördüncüsü, işlenmiş şeftaliden açığa çıkacak posa miktarını belirler; son denge kısıtı ise dağıtım ve toplama merkezine giren ve çıkan ürün miktarını eşitler. Kısıt (13)-Talep Kısıtt- perakendecilere gönderilen şeftali sularının talebi karşılaması gerektiğini; Kısıt (14), (15)-Kapasite Kısıtları- sırasıyla çiftçilerden ve 2. kademe tedarikçilerinden üretim merkezine taşınan şeftali miktarının ilgili çiftçi ve tedarikçinin kapasitesinden fazla olamayacağını; Kısıt (16) ve (17) -İşaret Kısıtları- ise karar değişkenlerinin negatif olmaması ve tamsayı olması gerektiğini göstermektedir.

\subsection{Sayısal Örnek ve Bulgular}

Bu bölümde, Türkiye'de faaliyet gösteren $X$ meyve suyu üreticisinin şeftali suyu-gıda tedarik zinciri ă̆ tasarımı problemi, önerilen sürdürülebilir modelin uygulanabilirliğini 
göstermek için kullanılmıştır. 1995 yılında yerli sermaye ile ticari hayatına başlayan $\mathrm{X}$ şirketi, \%100 meyve suyu üreten sektörün önde gelen firmalarından biri olarak hizmet vermektedir. Anonim şirketinin gizlilik politikası nedeniyle, şirketin adı ve vaka çalışmasındaki bazı veriler buradan değiştirilerek rapor edilmiştir. Modelin planlamas 3 periyot üzerinden yapılmıştır. Çiftçilerin olduğu 4 ayrı bölge, 3 ayrı 2. kademe tedarikçi, 6 perakendeci ve 1 'er üretim merkezi, cam şişe tedarikçisi, ambalaj tesisi, organik gübre tesisi, dağıtım ve toplama merkezi, geri dönüşüm merkezi ve çok sayıda müşteri bulunmaktadır. Üretim merkezinin müşterisi perakendecilerdir ve perakendeciler ile müşteriler arasındaki alış veriş dikkate alınmamaktadır. Ton başına şeftali işleme maliyeti (a) 500€ taşıma maliyeti (ta) 0,03モ iken litre başına şeftali suyu taşıma maliyeti 0,0005€ dir. Nihai ürün (12 litre şeftali suyu kolisi) satış fiyatı (sa) 40€, organik gübre merkezine ton başına şeftali posası satış fiyatı (sb) 60€, geri dönüşüm merkezine kullanılmış birim cam şişe satış fiyatı (sc) 0,10€ olarak ele alınmıştır. 1 litrelik cam şişe satın alma maliyeti (ps) 0,20€ iken birim karton kutu hacmi (g) 12 adet 1 litrelik şişe büyüklüğünde ve satın alma maliyeti ise ( $\boldsymbol{p k}) 0,15 €$ 'dır. 1 litre şeftali suyunun ağırlığ $(f) 0.0013$ ton ve stok maliyeti ise $(\boldsymbol{h}) 0.03 €$ 'dır. İşılenmiş şeftaliden açığa çıkan posa yüzdesi $(\boldsymbol{\beta}) \mathbf{0 . 2 0}$, geri dönen şişe yüzdesi $(\boldsymbol{\alpha}) 0.40$ ve yeniden kullanılacak şişe yüzdesi $(\gamma) 0.17$ 'dir. Ürün talebi her zaman birimi için 7 adettir. Üretim merkezi ile dağıtım ve toplama merkezi arasındaki mesafe (dd) 1500 km'dir. Diğer parametreler aşağıda Tablo 2, Tablo 3 ve Tablo 4'de verilmiştir.

Tablo 2. Şeftali satın alma maliyetleri (‡)

\begin{tabular}{|c|c|c|c|c|}
\hline & & \multicolumn{3}{|c|}{ Periyot } \\
\hline & & 1 & 2 & 3 \\
\hline \multirow{5}{*}{ Çiftçi bölgeleri } & 1 & 500 & 450 & 520 \\
\hline & 2 & 550 & 500 & 570 \\
\hline & 3 & 530 & 480 & 550 \\
\hline & 4 & 515 & 460 & 565 \\
\hline & & 1 & 2 & 3 \\
\hline \multirow{3}{*}{ 2. kademe tedarikçiler } & 1 & 590 & 510 & 600 \\
\hline & 2 & 630 & 560 & 650 \\
\hline & 3 & 620 & 550 & 630 \\
\hline
\end{tabular}

Tablo 3. Tedarik zinciri üyeleri arasındaki mesafeler $(\mathrm{km})$ ve kapasiteler (ton)

\begin{tabular}{|l|c|c|c|c|c|c|}
\hline & $\mathbf{1}$ & $\mathbf{2}$ & $\mathbf{3}$ & $\mathbf{4}$ & $\mathbf{5}$ & $\mathbf{6}$ \\
\hline$d c_{i}$ & 3000 & 3020 & 3015 & 2980 & & \\
\hline$d t_{j}$ & 200 & 185 & 160 & & & \\
\hline$d p_{k}$ & 100 & 120 & 200 & 210 & 178 & 150 \\
\hline$C c_{i}$ & 98 & 80 & 75 & 150 & & \\
\hline$C t_{j}$ & 60 & 70 & 75 & & & \\
\hline
\end{tabular}


Tablo 4. Müşteri talepleri (lt)

\begin{tabular}{|l|l|l|l|l|}
\hline & \multicolumn{5}{|l|}{ Periyot } & $\mathbf{3}$ \\
\hline \multirow{5}{*}{ Perakendeciler } & \multicolumn{1}{l}{$\mathbf{3}$} & $\mathbf{2}$ & $\mathbf{3}$ \\
\hline & $\mathbf{1}$ & 20000 & 36000 & 30000 \\
\cline { 2 - 5 } & $\mathbf{2}$ & 32000 & 30000 & 15000 \\
\cline { 2 - 5 } & $\mathbf{3}$ & 30000 & 20000 & 23000 \\
\cline { 2 - 5 } & $\mathbf{4}$ & 25000 & 40200 & 25000 \\
\hline & $\mathbf{5}$ & 40000 & 40900 & 40000 \\
\hline & $\mathbf{6}$ & 30000 & 30900 & 30000 \\
\hline
\end{tabular}

Geliştirilen karma tam sayılı doğrusal programlama modeli bu veriler doğrultusunda, Windows 10 işletim sistemi üzerinde çalışan $16 \mathrm{~GB}$ RAM'li $2.20 \mathrm{GHz}$ Intel ${ }^{\circledR}$ Core $^{\mathrm{TM}}$ i7-8750H CPU işlemciye sahip bir bilgisayarda GAMS 24.0.1/CPLEX paket programı kullanılarak 1 saniyeden kısa bir sürede çözülmüş ve aşağıdaki sonuçlar elde edilmiştir (Tablo 5).

Tablo 5. Optimal amaç fonksiyonu değeri (‡)

\begin{tabular}{|l|l|}
\hline Amaç Fonksiyonu & Değeri \\
\hline TG & 1821686.09 \\
\hline TM & 1494672.96 \\
\hline TSM & 555716.23 \\
\hline TÜM & 437131.50 \\
\hline TTM & 498017.28 \\
\hline SM & 3807.96 \\
\hline Z & $\mathbf{3 2 7 0 1 3 . 1 2}$ \\
\hline
\end{tabular}

Çözüm sonuçlarına göre toplam gelir 1821686.09€, toplam maliyet 1494672.96€, karı maksimize eden optimum amaç fonksiyonu değeri ise 327013.12€'dir. Firma için mali giderler olarak en fazla satın alma sonrasında sırasıyla taşıma, üretim ve stok kalemleri gelmektedir. Tüm dönemlerin optimal akışı Şekil 2>de gösterilmektedir. 

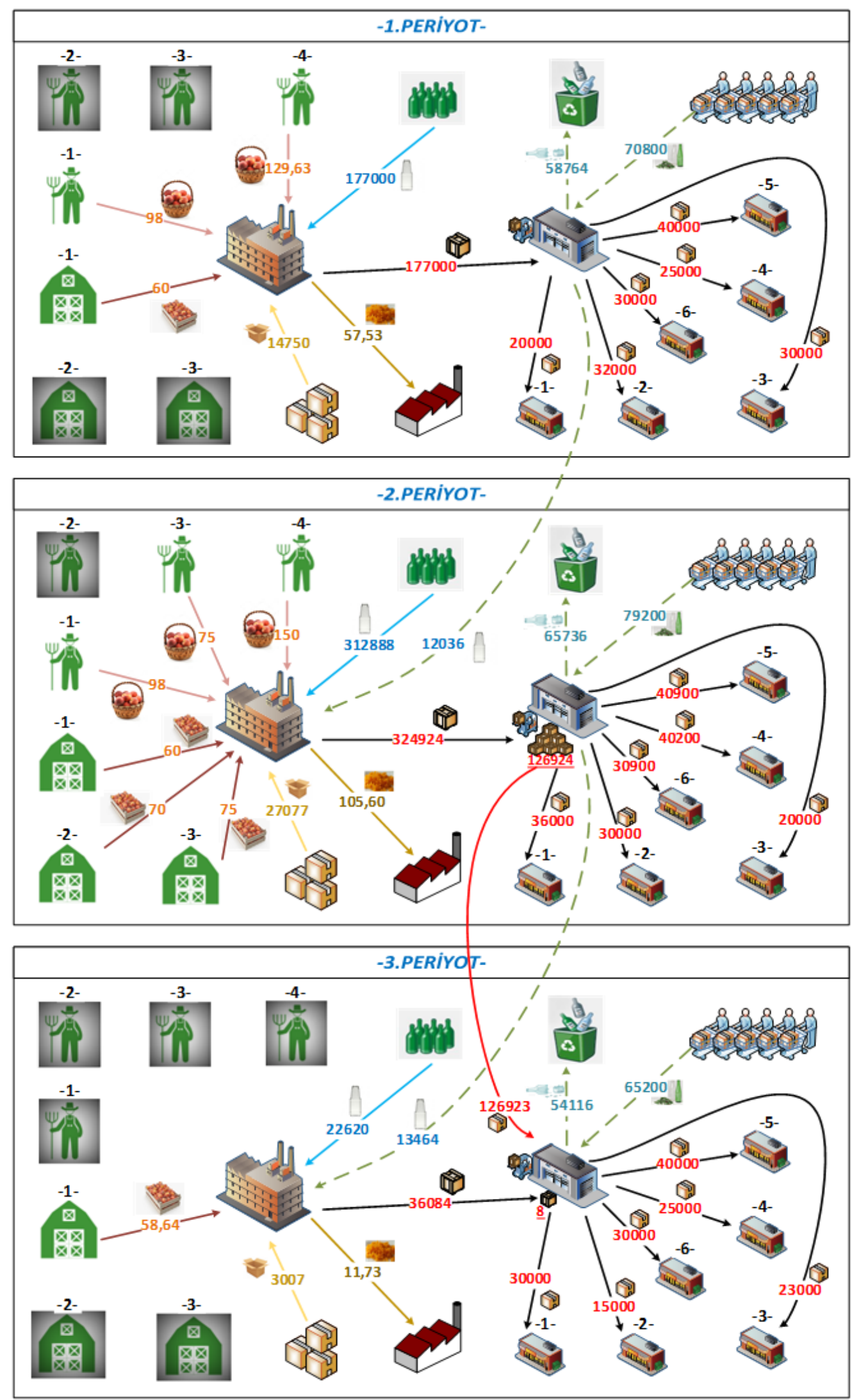

Şekil 2. Optimal Akış 


\section{Tartışma}

Bu bölümünde çözüm sonucu elde edilen bulgular Şekil 2 üzerinden açıklanmıştır. Burada kara kutu içerisinde gösterilen çiftçi ve 2. kademe tedarikçileri, ilgili dönemde aktif olmayan, herhangi bir satış gerçekleştirmeyen elemanları resmetmektedir. Düz çizgili oklar ileri, kesikli çizgiler tersine akışları göstermektedir. Çizgilerin üzerindeki sayılar akış miktarını, oklar ise akış yönünü belirtmektedir. Buna göre; Firma ilk dönem satın alma maliyetleri daha düşük olan 1 ve 4 numaralı bölgelerde bulunan çiftçilerden ve 1 numaral 2 . kademe tedarikçisinden şeftali temin ederek üretimi gerçekleştirmiştir. İkinci dönem ise şeftali maliyetlerinin düşüşüyle birlikte 2 numaralı bölgede bulunan çiftçiler dışında tüm çiftçi ve tedarikçilerden mümkün olduğunca şeftali temin ederek hem 2. dönemin talebini hem de sonraki dönem talebinin büyük kısmını karşılayacak şekilde üretim yapmıştır. Böylece dağıtım ve toplama merkezinde fazla şeftali suyu stoku tutarak bir sonraki dönemde beklenen hammadde fiyat artışı sebebiyle oluşacak zararın önüne geçmiştir. Ayrıca, üretilen şeftali suyunu şişelemek için bir önceki dönem toplanan cam şişelerden uygun olanlar dezenfekte edilip kullanılmış kalan kısım ise cam şişe tedarikçisinden satın alınarak karşılanmıştır. Son dönem ise kalan talebi karşılamak için sadece 1 numaralı tedarikçiden şeftali temin edilerek üretim gerçekleştirilmiş, kalan kısım dağıtım ve toplama merkezindeki stoktan karşılanmıştır. Yine şişelemek için hem önceki dönem toplanıp dezenfekte edilen hem de satın alınan yeni şişeler kullanılmıştır.

Geliştirilen modele ait çözüm sonuçlarının işletmenin karını artırmak üzerine iyileştirilmesi için, duyarlılık analizi yapılacak ve elde edilen bulgular genişletilecektir. İşletme için mali giderler bazında satın alma kalemi en fazla olduğundan, bir sonraki aşamada çiftçi ve 2. kademe tedarikçilerin tedarik zincirine ektisi üzerine bir analiz gerçekleştirilecektir.

\subsection{Duyarlılık Analizi}

Bu bölümde oluşturulan model için Çiftçi ve 2. Kademe tedarikçi kapasite parametreleri değerlerindeki değişimin, problemin amaç fonksiyonu değeri ve ağ tasarımı üzerine olan etkileri incelenmiştir. Tablo 6'deki sonuçlara göre çiftçi kapasiteleri artıkça amaç fonksiyonu değeri de genel olarak artmaktadır. Çiftçi kapasiteleri $\% 25, \% 50, \% 75$ ve $\% 100$ arttırıldığında toplam kâr sırasıyla \%0.8, \%1.3, \%1.8 ve \%2.1'lik bir artış göstermiştir. Ayrıca Tablo 6'den elde edilen verilere göre tüm senaryolarda 1. Çiftçiden ilk iki dönem, 4. Çiftçiden ise sadece ikinci dönem ( şeftali fiyatlarının düştüğü sezon) ful kapasite ürün satın alınmıştır. Çiftçi kapasiteleri artırıldıkça firma öncelikle bu tedarikçilerden ürün almaya yöneldiğinden 3 numaralı çiftçiden ilk senaryodan sonra 2 numaralı çiftçiden ise hiçbir senaryoda ürün satın alınmamıştır.

Tablo 7'daki sonuçlara göre 2. Kademe tedarikçi kapasiteleri artıkça yine amaç fonksiyonu değeri de genel olarak artmaktadır. 2. Kademe tedarikçi kapasiteleri $\% 25, \% 50, \% 75$ ve \%100 arttırıldığında toplam kâr sırasıyla \%0.6, \%1, \%1.3 ve \%1.7’lik bir artış göstermiştir. Ayrıca Tablo 7'dan elde edilen verilere göre tüm senaryolarda 1. tedarikçiden ilk iki dönem, 3 . tedarikçiden ise sadece ikinci dönem ful kapasite ürün satın alınmıştır. Yine, 2. Tedarikçiden 2. dönem ilk iki senaryoda ful kapasite sonraki senaryolarda ise firma öncelikle 1 ve 3 numaralı tedarikçilerden ürün almaya yöneldiğinden kapasitesinin altında ürün satın alınmıştır. 
Buradan hareketle, çiftçi ve tedarikçilerin etkinliği üzerine yapılan duyarlılık analizleri sonucunda, doğru ( en uygun) çiftçileri tarlalarını daha verimli hale getirmeleri üzerine teşvik ederek daha fazla miktarda ürün çıkmasını sağlamak; yine doğru tedarikçileri de satın alma sözü üzerine hasat zamanı daha fazla ürün temin etmeleri konusunda teşvik etmek, firmanın satın alma maliyetlerini büyük ölçüde düşürecek ve kârı en büyükleme amacına dair büyük avantaj kazandıracaktır. Bu açıdan, Tablo 6 ve 7 da sunulan duyarlılık analizleri sonucuna göre; Firmanın daha fazla kâr elde etmek için öncelikli olarak kendisi için en uygun olan 1 numaralı çiftçi ve tedarikçi ile sonrasında gerekirse 4 numaralı çiftçi ve 3 numaralı tedarikçi ile bir anlaşma yoluna gitmesi önerilir.

Tablo 6. Senaryo analizi sonucu çiftçilerden ürün akışı ve amaç fonksiyonu performans değerleri

\begin{tabular}{|l|c|c|c|c|c|}
\hline & \multicolumn{5}{|c|}{ Çiftçi kapasitelerinin değişimi } \\
\hline Performanslar & Mevcut & $+\mathbf{+ 0 2 5}$ & $+\mathbf{+ 0 5 0}$ & $+\mathbf{+ 7 5}$ & $\mathbf{+ \% 1 0 0}$ \\
\hline $\boldsymbol{C c}_{\boldsymbol{1}}$ & $\mathbf{9 8}$ & $\mathbf{1 2 2 . 5}$ & $\mathbf{1 4 7}$ & $\mathbf{1 7 1 . 5}$ & $\mathbf{1 9 6}$ \\
\hline$X_{11}$ & 98 & 122.5 & 147 & 171.5 & 196 \\
\hline$X_{12}$ & 98 & 122.5 & 147 & 171.5 & 196 \\
\hline$X_{13}$ & 0 & 0 & 0 & 0 & 0 \\
\hline $\boldsymbol{C c}_{2}$ & $\mathbf{8 0}$ & $\mathbf{1 0 0}$ & $\mathbf{1 2 0}$ & $\mathbf{1 4 0}$ & $\mathbf{1 6 0}$ \\
\hline$X_{21}$ & 0 & 0 & 0 & 0 & 0 \\
\hline$X_{22}$ & 0 & 0 & 0 & 0 & 0 \\
\hline$X_{23}$ & 0 & 0 & 0 & 0 & 0 \\
\hline $\boldsymbol{c}_{3}$ & $\mathbf{7 5}$ & $\mathbf{9 3 . 7 5}$ & $\mathbf{1 1 2 . 5}$ & $\mathbf{1 3 1 . 2 5}$ & $\mathbf{1 5 0}$ \\
\hline$X_{31}$ & 0 & 0 & 0 & 0 & 0 \\
\hline$X_{32}$ & 75 & 49.76 & 0 & 0 & 0 \\
\hline$X_{33}$ & 0 & 0 & 0 & 0 & 0 \\
\hline $\boldsymbol{c}_{4}$ & $\mathbf{1 5 0}$ & $\mathbf{1 8 7 . 5}$ & $\mathbf{2 2 5}$ & $\mathbf{2 6 2 . 5}$ & $\mathbf{3 0 0}$ \\
\hline$X_{41}$ & 129.63 & 105.13 & 80.63 & 56.13 & 31.62 \\
\hline$X_{42}$ & 150 & 187.5 & 225 & 262.5 & 300 \\
\hline$X_{43}$ & 0 & 0 & 0 & 0 & 0 \\
\hline $\mathbf{Z}$ & $\mathbf{3 2 7 0 1 3 . 1 2}$ & $\mathbf{3 2 9 5 2 9 . 4 8}$ & $\mathbf{3 3 1 3 5 7 . 7 0}$ & $\mathbf{3 3 2 8 9 6 . 5 1}$ & $\mathbf{3 3 3 8 1 4 . 4 1}$ \\
\hline
\end{tabular}

Tablo 7. Senaryo analizi sonucu 2. kademe tedarikçi ürün akışı ve amaç fonksiyonu performans değerleri.

\begin{tabular}{|l|c|c|c|c|c|}
\hline & \multicolumn{5}{|c|}{ 2. Kademe tedarikçi kapasitelerinin değişimi } \\
\hline Performanslar & Mevcut & $\mathbf{+ \% 2 5}$ & $\mathbf{+ \% 5 0}$ & $\mathbf{+ \% 7 5}$ & $\mathbf{+ \% 1 0 0}$ \\
\hline $\boldsymbol{C t}_{\boldsymbol{1}}$ & $\mathbf{6 0}$ & $\mathbf{7 5}$ & $\mathbf{9 0}$ & $\mathbf{1 0 5}$ & $\mathbf{1 2 0}$ \\
\hline$Y_{11}$ & 60 & 75 & 90 & 105 & 120 \\
\hline$Y_{12}$ & 60 & 75 & 90 & 105 & 120 \\
\hline$Y_{13}$ & 58.64 & 21.88 & 21.88 & 21.88 & 21.88 \\
\hline $\boldsymbol{C t}_{2}$ & $\mathbf{7 0}$ & $\mathbf{8 7 . 5}$ & $\mathbf{1 0 5}$ & $\mathbf{1 2 2 . 5}$ & $\mathbf{1 4 0}$ \\
\hline$Y_{21}$ & 0 & 0 & 0 & 0 & 0 \\
\hline$Y_{22}$ & 70 & 87.5 & 105 & 80.51 & 46.76 \\
\hline$Y_{23}$ & 0 & 0 & 0 & 0 & 0 \\
\hline $\boldsymbol{C t}_{\mathbf{3}}$ & $\mathbf{7 5}$ & $\mathbf{9 3 . 7 5}$ & $\mathbf{1 1 2 . 5}$ & $\mathbf{1 3 1 . 2 5}$ & $\mathbf{1 5 0}$ \\
\hline$Y_{31}$ & 0 & 0 & 0 & 0 & 0 \\
\hline$Y_{32}$ & 75 & 93.75 & 112.5 & 131.25 & 150 \\
\hline$Y_{33}$ & 0 & 0 & 0 & 0 & 0 \\
\hline $\mathbf{Z}$ & $\mathbf{3 2 7 0 1 3 . 1 2}$ & $\mathbf{3 2 8 9 6 3 . 2 2}$ & $\mathbf{3 3 0 2 8 5 . 1 6}$ & $\mathbf{3 3 1 4 0 1 . 3 4}$ & $\mathbf{3 3 2 4 7 2 . 1 5}$ \\
\hline
\end{tabular}


Bunun yanında çiftçi ve 2. Kademe tedarikçi kapasite değerleriyle yapılan duyarlılık analizlerinin amaç fonksiyonuna ektileri üzerindeki fark Şekil 3'de daha açık bir şekilde gösterilmiştir. Buna göre, çiftçi kapasiteleri üzerine yapılan değişiklikler kâr üzerinde, 2. Kademe tedarikçilerine oranla daha büyük artışlara neden olmuştur. Bu da gösteriyor ki önerilen model, çiftçi kapasitesi parametre değişikliklerine daha duyarlıdır.

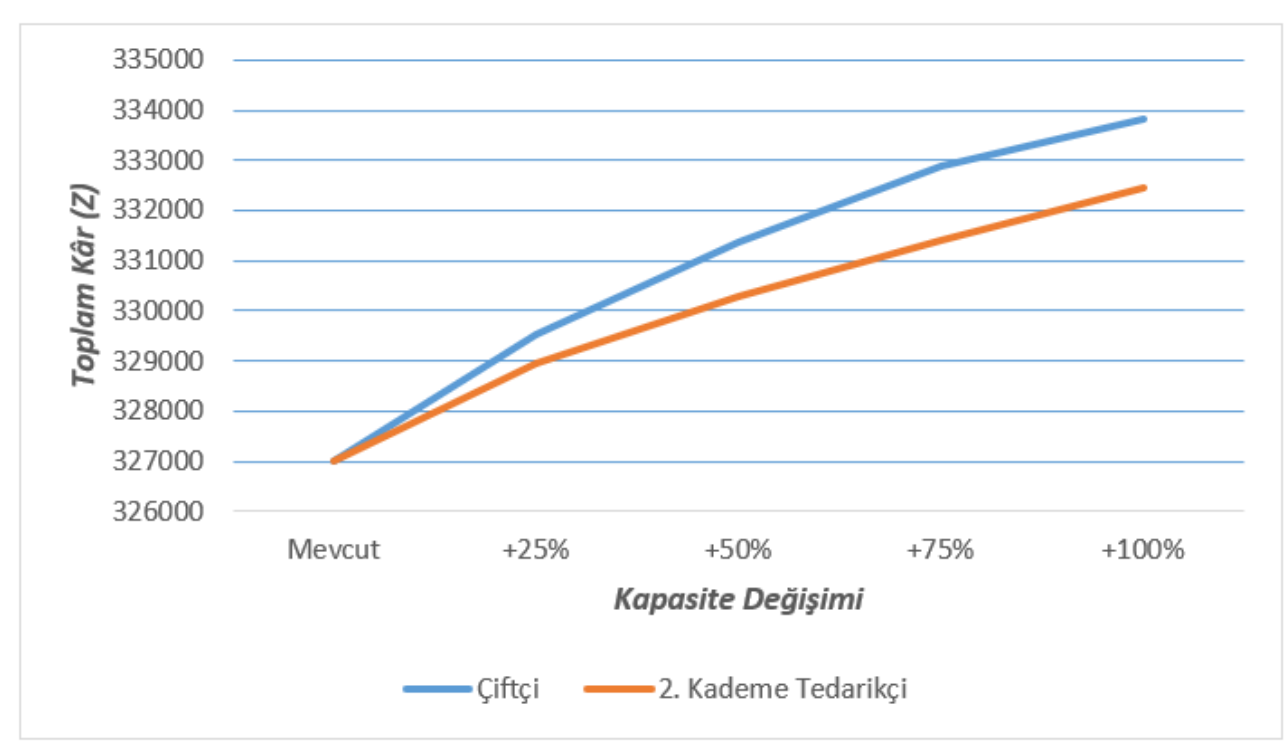

Şekil 2. Duyarlılık analizi sonucu amaç fonksiyonundaki performans değişimi

\section{SONUÇ}

Gıda, günlük yaşamın hayati bir bileşenidir, ancak mevcut tüketim ve üretim kalıpları çevre ve gelecek nesillerin gıda güvenliği için bir tehdit oluşturmaktadır. Üretilen tarımsal gıda ürünleri, yetersiz altyapı ve verimsiz TZ ağları nedeniyle israf edilmektedir. Bu nedenle, çevresel sorumlulukların ve toplumsal farkındalığın artmasıyla birlikte, gıda tedarik sistemini yeniden gözden geçirmenin zamanı gelmiştir (Rohmer vd., 2019). Firmaların, mevcut yaklaşımlarıyla birlikte sürdürülebilir paradigmaları da uygulamaları rakiplerine karşı avantaj sağlamaktadır. Bu doğrultuda, Gıda sektöründe faaliyet gösteren bir meyve suyu firması için yeni bir TZ ağ tasarımı oluşturulmuştur. Yapılan duyarlılık analizi ile uygun çiftçi ve tedarikçilerden yeterli arz sağlanmasının, maliyet artışının önüne geçeceği ve meyve suyu üretim sürecine daha yüksek kâr kazandıracağı sonucuna varılmıştır.

Meyve Suyu Endüstrisi Derneği 2020 yılı şubat ayında Türkiye'deki yıllık meyve suyu tüketiminin 1 milyar litre olduğunu açıklamıştır. Bu çalışma, mevcut yayınlardan farklı olarak meyve suyu tedarik zincirinde geri dönüşüme yeterli önemi vermesi ve sürdürülebilir bir ağ tasarımı oluşturması bakımından literatüre katkı sağlamaktadır. Çalışmanın pratik hayata katkısı ise önerilen modelin uygulanması halinde meyve suyu üretim sürecinin daha verimli ve sürdürülebilir biçimde planlanacağı, hem çiftçilerin hem de firmanın çevresel ve ekonomik kazanım elde edeceği sonucudur.

$\mathrm{Bu}$ çalışmada sunulan model çerçevesi, uygulayıcılara tarım-gıda tedarik zincirinde ağ tasarımı modelleme ve tasarım sürecine dâhil edilmesi gereken temel konularda rehberlik etmek için geliştirilmiştir. Ayrıca tarımsal gıda sistemlerinde sıklıkla ortaya 
çıkan durumların nasıl üstesinden gelineceğine dair örnekler sunmaktadır. Şeftali suyu üretim süreci uygulama çalışması, sunulan modelleme ve optimizasyon stratejileri için örnek bir vaka işlevi görür ve benzer özelliklere sahip çok çeşitli tarımsal gıda tedarik zincirlerine uygulanabilir.

Peer-review: Externally peer-reviewed.

Conflict of Interest: The authors have no conflict of interest to declare.

Grant Support: The authors declared that this study has received no financial support.

Hakem Değerlendirmesi: Dış bağımsız.

Çıkar Çatışması: Yazarlar çıkar çatışması bildirmemiştir.

Finansal Destek: Yazarlar bu çalışma için finansal destek almadığını beyan etmiştir.

\section{Kaynakça}

Akkerman, R., Farahani, P., \& Grunow, M. (2010). Quality, safety and sustainability in food distribution: A review of quantitative operations management approaches and challenges. Operations ResearchSpektrum, 32, 863-904. https://doi.org/10.1007/s00291-010-0223-2

Allaoui, H., Guo, Y., Choudhary, A., \& Bloemhof, J. (2018). Sustainable agro-food supply chain design using two-stage hybrid multi-objective decision-making approach. Computers and Operations Research, 89, 369-384. https://doi.org/10.1016/j.cor.2016.10.012

Apaiah, R. K., \& Hendrix, E. M. T. (2005). Design of a supply chain network for pea-based novel protein foods. Journal of Food Engineering, 70(3), 383-391. https://doi.org/https://doi.org/10.1016/j. jfoodeng.2004.02.043

Barsing, P., Daultani, Y., Vaidya, O. S., \& Kumar, S. (2018). Cross-docking Centre Location in a Supply Chain Network: A Social Network Analysis Approach. Global Business Review, 19(3_suppl), S218-S234. https://doi.org/10.1177/0972150918757847

Biuki, M., Kazemi, A., \& Alinezhad, A. (2020). An integrated location-routing-inventory model for sustainable design of a perishable products supply chain network. Journal of Cleaner Production, 260, 120842. https://doi.org/https://doi.org/10.1016/j.jclepro.2020.120842

Bortolini, M., Galizia, F. G., Mora, C., Botti, L., \& Rosano, M. (2018). Bi-objective design of fresh food supply chain networks with reusable and disposable packaging containers. Journal of Cleaner Production, 184, 375-388. https://doi.org/10.1016/j.jclepro.2018.02.231

Bortolini, Marco, Faccio, M., Ferrari, E., Gamberi, M., \& Pilati, F. (2016). Fresh food sustainable distribution: cost, delivery time and carbon footprint three-objective optimization. Journal of Food Engineering, 174, 56-67. https://doi.org/https://doi.org/10.1016/j.jfoodeng.2015.11.014

Cascini, A., Mora, C., Pareschi, A., \& Ferrari, E. (2014). Multi-objective optimisation modelling for Green Supply Chain Management. Proceedings of the Summer School Francesco Turco, 2014-Janua, 19-24.

Colicchia, C., Creazza, A., Dallari, F., \& Melacini, M. (2016). Eco-efficient supply chain networks: Development of a design framework and application to a real case study. Production Planning and Control, 27(3), 157-168. https://doi.org/10.1080/09537287.2015.1090030

Darestani, S. A., \& Hemmati, M. (2019). Robust optimization of a bi-objective closed-loop supply chain network for perishable goods considering queue system. Computers \& Industrial Engineering, 136, 277-292. https://doi.org/https://doi.org/10.1016/j.cie.2019.07.018

Das, K. (2019). Integrating lean, green, and resilience criteria in a sustainable food supply chain planning model. International Journal of Mathematical, Engineering and Management Sciences, 4(2), 259-275. https://doi.org/10.33889/ijmems.2019.4.2-022 
Dunne, J. B., Chambers, K. J., Giombolini, K. J., \& Schlegel, S. A. (2011). What does local mean in the grocery store? Multiplicity in food retailers' perspectives on sourcing and marketing local foods. Renewable Agriculture and Food Systems, 26(1), 46-59. https://doi.org/10.1017/S1742170510000402

Duram, L. A., \& Cawley, M. (2012). Irish chefs and restaurants in the geography of "local" food value chains. Open Geography Journal, 5(1), 16-25. https://doi.org/10.2174/1874923201205010016

Ghanbari, S., \& Bashiri, M. (2019). A Resilient Agribusiness Supply Chain Network Design in a Two-Stage Stochastic Programming Framework. Proceedings of 2019 15th Iran International Industrial Engineering Conference, IIIEC 2019, 184-188. https://doi.org/10.1109/IIIEC.2019.8720637

Gholamian, M. R., \& Taghanzadeh, A. H. (2017). Integrated network design of wheat supply chain: A real case of Iran. Computers and Electronics in Agriculture, 140, 139-147. https://doi.org/https://doi. org/10.1016/j.compag.2017.05.038

Gong, W., Li, D., Liu, X., Yue, J., \& Fu, Z. (2007). Improved two-grade delayed particle swarm optimisation (TGDPSO) for inventory facility location for perishable food distribution centres in Beijing. New Zealand Journal of Agricultural Research, 50(5), 771-779. https://doi.org/10.1080/00288230709510350

Govindan, K., Jafarian, A., Khodaverdi, R., \& Devika, K. (2014). Two-echelon multiple-vehicle locationrouting problem with time windows for optimization of sustainable supply chain network of perishable food. International Journal of Production Economics, 152, 9-28. https://doi.org/https://doi.org/10.1016/j. ijpe.2013.12.028

Hasani, A., Zegordi, S. H., \& Nikbakhsh, E. (2012). Robust closed-loop supply chain network design for perishable goods in agile manufacturing under uncertainty. International Journal of Production Research, 50(16), 4649-4669. https://doi.org/10.1080/00207543.2011.625051

Jain, V., Wadhwa, S., \& Deshmukh, S. G. (2009). Select supplier-related issues in modelling a dynamic supply chain: Potential, challenges and direction for future research. International Journal of Production Research. https://doi.org/10.1080/00207540701769958

Jiang, Y., Zhao, L., \& Sun, S. (2009). A resilient strategy for meat-food supply chain network design. IEEM 2009- IEEE International Conference on Industrial Engineering and Engineering Management, 1479-1483. https://doi.org/10.1109/IEEM.2009.5373072

Jouzdani, J., \& Govindan, K. (2021). On the sustainable perishable food supply chain network design: A dairy products case to achieve sustainable development goals. Journal of Cleaner Production, 278, 123060. https://doi.org/10.1016/j.jclepro.2020.123060

Miranda-Ackerman, M. A., Azzaro-Pantel, C., \& Aguilar-Lasserre, A. A. (2017). A green supply chain network design framework for the processed food industry: Application to the orange juice agrofood cluster. Computers and Industrial Engineering, 109, 369-389. https://doi.org/10.1016/j.cie.2017.04.031

Mogale, D. G., Cheikhrouhou, N., \& Tiwari, M. K. (2020). Modelling of sustainable food grain supply chain distribution system: a bi-objective approach. International Journal of Production Research, 58(18), 5521-5544. https://doi.org/10.1080/00207543.2019.1669840

Mohammadi, Z., Barzinpour, F., \& Teimoury, E. (2020). Designing sustainable supply chain network by considering direct and indirect shipment: Evidence from food industry. Decision Science Letters, 323-336. https://doi.org/10.5267/j.dsl.2020.5.003

Mohammed, A., \& Wang, Q. (2017). Developing a meat supply chain network design using a multi-objective possibilistic programming approach. British Food Journal, 119(3), 690-706. https://doi.org/10.1108/ BFJ-10-2016-0475

Mohammed, A., Wang, Q., \& Filip, M. (2017c). Towards a cost-effective design of a meat supply chain: A multi-criteria optimization model. ICAC 2017 - 2017 23rd IEEE International Conference on Automation and Computing: Addressing Global Challenges through Automation and Computing. https://doi. org/10.23919/IConAC.2017.8082016

Mohammed, A., Wang, Q., \& Li, X. (2017a). A cost-effective decision-making algorithm for an RFID-enabled HMSC network design A multi-objective approach. Industrial Management and Data Systems, 117(9), 1782-1799. https://doi.org/10.1108/IMDS-02-2016-0074 
Mohammed, A., Wang, Q., \& Li, X. (2017b). A study in integrity of an RFID-monitoring HMSC. International Journal of Food Properties, 20(5), 1145-1158. https://doi.org/10.1080/10942912.2016.1203933

Nourbakhsh, S. M., Bai, Y., Maia, G. D. N., Ouyang, Y., \& Rodriguez, L. (2016). Grain supply chain network design and logistics planning for reducing post-harvest loss. Biosystems Engineering, 151, 105-115. https://doi.org/https://doi.org/10.1016/j.biosystemseng.2016.08.011

Ogier, M., Cung, V.-D., \& Boissière, J. (2013). Service network design in short and local fresh food supply chain. RAIRO Recherche Operationnelle, 47(4), 445-464. https://doi.org/10.1051/ro/2013051

Paksoy, T., Çalik, A., Kumpf, A., \& Weber, G. W. (2019). A new model for lean and green closed-loop supply chain optimization. Içinde T. Paksoy, G. W. Weber, \& S. Huber (Ed.), Lean and Green Supply Chain Management (C. 273, ss. 39-73). Springer International Publishing. https://doi.org/10.1007/9783-319-97511-5_2

Parwez, S. (2014). Food supply chain management in Indian Agriculture: Issues, opportunities and further research. African Journal of Business Management, 8, 572-581. https://doi.org/10.5897/AJBM2013.7292

Pourmohammadi, F., Teimoury, E., \& Gholamian, M. R. (2020). A scenario-based stochastic programming approach for designing and planning wheat supply chain (A case study). Decision Science Letters, 9(4), 537-546. https://doi.org/10.5267/j.ds1.2020.8.004

Pulker, C. E., Trapp, G. S. A., Scott, J. A., \& Pollard, C. M. (2018). What are the position and power of supermarkets in the Australian food system, and the implications for public health? A systematic scoping review. Obesity Reviews, 19(2), 198-218. https://doi.org/https://doi.org/10.1111/obr.12635

Qaim, M. (2017). Conference on "Sustainable food consumption" Globalisation of agrifood systems and sustainable nutrition. Proceedings of the Nutrition Society, 76(1), 12-21. https://doi.org/10.1017/ S0029665116000598

Renting, H., Marsden, T., \& Banks, J. (2003). Understanding Alternative Food Networks: Exploring the Role of Short Food Supply Chains in Rural Development. Environment and Planning A, 35, 393-411. https://doi.org/10.1068/a3510

Rohmer, S. U. K., Gerdessen, J. C., \& Claassen, G. D. H. (2019). Sustainable supply chain design in the food system with dietary considerations: A multi-objective analysis. European Journal of Operational Research, 273(3), 1149-1164. https://doi.org/10.1016/j.ejor.2018.09.006

Soysal, M., Bloemhof-Ruwaard, J. M., \& van der Vorst, J. G. A. J. (2014). Modelling food logistics networks with emission considerations: The case of an international beef supply chain. International Journal of Production Economics, 152, 57-70. https://doi.org/https://doi.org/10.1016/j.ijpe.2013.12.012

Validi, S., Bhattacharya, A., \& Byrne, P. J. (2014). A case analysis of a sustainable food supply chain distribution system - A multi-objective approach. International Journal of Production Economics, 152, 71-87. https://doi.org/https://doi.org/10.1016/j.ijpe.2014.02.003

Zhao, X., \& Lv, Q. (2011). Optimal design of agri-food chain network: An improved particle swarm optimization approach. International Conference on Management and Service Science, MASS 2011. https://doi.org/10.1109/ICMSS.2011.05998308 